\title{
Reliability Evaluation of Demand Response and TVTR considering the Cost of Interruptions
}

DOI:

10.1109/ISGTEurope.2014.7028890

Link to publication record in Manchester Research Explorer

\section{Citation for published version (APA):}

Kapetanaki, A., \& Kopsidas, K. (2014). Reliability Evaluation of Demand Response and TVTR considering the Cost of Interruptions. In IEEE PES Innovative Smart Grid Technologies (ISGT), Europe IEEE.

https://doi.org/10.1109/ISGTEurope.2014.7028890

\section{Published in:}

IEEE PES Innovative Smart Grid Technologies (ISGT), Europe

\section{Citing this paper}

Please note that where the full-text provided on Manchester Research Explorer is the Author Accepted Manuscript or Proof version this may differ from the final Published version. If citing, it is advised that you check and use the publisher's definitive version.

\section{General rights}

Copyright and moral rights for the publications made accessible in the Research Explorer are retained by the authors and/or other copyright owners and it is a condition of accessing publications that users recognise and abide by the legal requirements associated with these rights.

\section{Takedown policy}

If you believe that this document breaches copyright please refer to the University of Manchester's Takedown Procedures [http://man.ac.uk/04Y6Bo] or contact uml.scholarlycommunications@manchester.ac.uk providing relevant details, so we can investigate your claim.

\section{OPEN ACCESS}




\title{
Reliability Evaluation of Demand Response and TVTR considering the Cost of Interruptions
}

\author{
Alexandra Kapetanaki, Student Member IEEE, Konstantinos Kopsidas,Member IEEE
}

\begin{abstract}
Traditional transmission operation is mainly driven by passive consumer behaviour and predetermined static or seasonal overhead lines (OHLs) thermal ratings. However, in a smart operation scheme, which considers demand side management (DSM) regimes as well as time varying thermal ratings (TVTR) of transmission assets, network operation could be updated and optimally accommodate novel transmission reinforcement concepts. In this paper a reliability evaluation with incentive-based demand response (IBDR) is performed considering peak shaving and valley shifting (PSVS) in conjunction with emergency demand response (EDR).

The novelty of the proposed model is the inclusion of customer interruption frequency and interruption duration, based on the different customer types (residential, commercial, industrial, and large users), using probabilistic metrics to capture the total cost of network operation. The methodology is applied to the IEEE 24-bus reliability test system with a more advanced modelling of OHLs to facilitate the inclusion of TVTR. From this analysis increased benefits from DSM are evident when TVTR is implemented and considerably improves network performance.
\end{abstract}

Keywords—adequacy, IBDR, EDR, thermal rating, reliability, network security, sequential modelling

\section{INTRODUCTION}

The impact of many demand response programs have been mainly evaluated for distribution systems (DS), whereas the effect of these programs on the transmission system (TS) has either been ignored or treated as a minor issue. The integration of DSM strategy on the TS operation and planning process has proven to be cost effective, while at the same time improve the security and reliability of the system. As a result, much attention is now being placed on performing probabilistic reliability assessment by considering DR programs in a composite power system operating paradigm. EDR is proposed in [1] using the elasticity of demand to improve nodal reliability indexes of the RBT system while a state enumeration technique is used for the computation of the indexes. According to [2], PSVS modeling is used for the DR combined with a strategic conversion and load growth modeling. The IEEE RTS is used for the illustration of the proposed methodology under sequential Monte-Carlo (MC) modeling to evaluate the reliability indices with and without DR. The prioritization of implementing various DR programs from the view-point of different market participants is evaluated in [3] using enumeration techniques. This method is built considering the Energy Expected Not Supplied (EENS) index and the Value of Loss of Load (VOLL) of the customers. The IEEE RTS system is used to test the reliability indices of both generation and transmission.
Considering the DR models proposed in the literature for reliability assessment of T\&D networks, very little research includes consumers' socio-economic interruption costs. However, interruption costs significantly affect the reliability worth evaluation [4], which can optimally be reduced by DSM. Several approaches evaluate the value that customers introduce to the total operating cost and associate it with the lack of energy supply. The most common one is related to customer surveys that seek to estimate the outage costs that would be experienced if supply was interrupted [5]. These outage costs, also called value of lost load (VOLL), express the duration of interruption of different sectors in $\$ / \mathrm{KWh}$.

In addition, recent interest has focused on the employment of dynamic thermal rating (DTR) in the transmission system modelling in view of enhancing system flexibility and reliability. Only a few reliability analyses of networks with DTR exist in the literature. For instance, network planning evaluation with TVTR is used in [6]. An iterative procedure is implemented for the proposed TVTR, which is evaluated under both deterministic and probabilistic frameworks. It is shown that the annual operating costs are reduced when the real transfer capability and transmission losses of the OHLs are accounted for. In [7] a reliability assessment methodology is proposed that considers DTR, based on randomly generated ratings using a normal probability distribution function (PDF).

In this context, this paper demonstrates the benefits of implementing IBDR based on proposed probabilistic indices that capture more accurately the interruption costs of customers in a transmission network. In addition, expected contingency VOLL (ECVOLL) is determined, which contributes to a more detailed calculation of the nodal electricity price in a competitive spot market. It also extends the analysis of DR further by considering TVTR modelling of the lines, and thus provides the network operator with greater flexibility and reduced operational costs in the emerging smart grid paradigm.

\section{NETWORK MODELLING CONSIDERING DR OPERATION SCHEME}

\section{A. Proposed Peak Shaving and Valley Filling Strategy}

By definition, peak clipping DSM means that peak energy is reduced by the DSM actions and can be completely or partly recovered during off peak hours [8]. Six load shaping objectives of DSM have been realized [9], i.e., peak clipping, valley filling, load shifting, strategic load growth, strategic conservation and load shaping. While historically these DSM mechanisms were initially applied by industry to achieve fuel or generation capacity savings, they are now increasingly being employed to increase T\&D utilization caused by the significant proliferation of renewable generation. 
In this work, peak energy is reduced in accordance with the proposed probabilistically calculated weight indexes, and consequently this energy is shifted during off peak hours. Based on [2] the hourly load $\mathrm{L}(\mathrm{t})$ is given by:

$$
L(t)=\left\{\begin{array}{c}
L(t)-A t \in \Omega \\
L(t)+A t \in \Psi=\left[t_{1}+t_{2}\right]
\end{array}\right\}
$$

$$
A=D R f_{-} P S V S+D R f_{-} e m
$$

A:

DRf_PSVS

MW load shifted/filled in peak/off peak hour

DRf_em: DR value under PSVS condition

\section{$N_{b}$ :} Demand response function determining the DR value under emergency condition

$N_{s}$ : Number of load points

$\Psi:$ Number of customer types Set of peak hours during which the energy is shifted and $t_{1}, t_{2}$ denoting the starting and ending times, respectively

However, consumers' intention to meet the curtailed demand at an off peak time is uncertain. Furthermore, it is likely that the total energy consumption will become higher than the energy consumed during peak load. To avoid this, the hourly energy consumption is pre-specified to be no more or less than $20 \%$ of the initial energy consumption. A least square optimization method is implemented to keep the load within specific limits.

For the computation of DRf_PSVS, the uncertainty of generation and transmission lines is considered (baseline) in order to determine the importance of each load point using weight factors, and therefore estimate the demand response value. In particular, the weight indexes incorporate the frequency and the duration of the customer's interruptions (WIbus) and the interruption cost of each customer type (WIICCbas). The DR function can therefore be expressed as follows:

$$
\begin{aligned}
& D R f_{-} P S V S=\sum_{j=1}^{N b}\left(\sum_{i=1}^{N s} \text { WIbus }_{j} \times\left(1-\text { WIICCbas }_{i}\right) \times L \sec t_{i, j}\right)(1.3) \\
& \text { WIbus }_{j}=\frac{\sum_{m=1}^{N_{t}} N I_{m} \times D i_{m}}{\text { Samples }} \\
& \text { WIICCbas }_{j, i}=\frac{\text { EENS }_{j, i} \times \text { VOLL }_{i}^{D i}}{\text { Simulation_year }_{\text {year }}} \\
& L \sec t_{i, j}=Y \times \text { Lbus }
\end{aligned}
$$

WIbus $_{j}$ : $\quad$ Weight index, which shows the importance of each bus in terms of demand interruptions under the baseline

WIICCbas $_{j, i}$ : Effect of the interruption cost of the customer to the demand response value

$N I$ :

$Y$ : Number of customer's interruptions Percentage of customer types at each bus

Lsect $_{i, j}: \quad \quad$ Customer sectors of each bus $\mathrm{j}$

Di: $\quad$ Duration of customer's interruption

$N_{t}$ : $\quad$ Interruption duration, lasting up to 24 hours
The calculation of WIICCbas is described in [10]. The VOLL is expressed in $\$ / \mathrm{KWh}$ and is given by [5] for various chronological intervals of interruptions of residential, commercial, industrial and large users.

\section{B. Proposed Emergency Demand Response strategy}

Emergency demand response (EDRP) is the most usual DR program when an event occurs. EDRP provides incentives for customers to reduce loads during reliability events, though the curtailment is voluntary. No penalty is applied if costumers do not curtail; rates are pre-specified and no capacity payments are received [11]. EDR allows the Independent System Operator (ISO) to avoid exposure to price risk by considering historical demand, price data and short term load forecasting [12]. According to [11], a customer chooses the interruption time and duration (in hours) during an electricity shortfall and is compensated via a bidding process. An EDR program was applied in the USA (in 2005) showing very good results with respect to both the load shape and the normalizing of the price [11]. Customers receive a payment 10 times higher than the electricity price in the off-peak period, but no penalty is incurred if no action is taken. In [13] EDRP and Time-of-Use (TOU) programs are considered simultaneously based on a load elasticity model.

In this study, EDR is applied under security violations in order to reduce the curtailed energy based on the customers' interruption duration and cost at a given hour. A weight factor comprising of the statistical mode value of the duration of the interruptions (WIFD) has been estimated under the baseline. Hence, for the first recorded hour that a load point is interrupted, the corresponding WIFD is plugged into the interruption cost calculation of each customer type. In the case, the interruption lasts more than the given WIFD the interruption cost is updated with the new Di. Thus the priority of EDR of each bus is set proportionally to the total bus interruption cost subject to WIFD, while the amount of curtailed energy at each customer sector is controlled through WIICCor. As such, the computation of the DR function under emergency condition is given by the following formula:

$$
\begin{aligned}
& \text { DRf_em }=\sum_{j=1}^{N b}\left(\sum_{i=1}^{N s}\left(1-\text { WIICCor }_{i}\right) \times L \sec t_{i, j} \times \text { WIFD }_{j} \times L O L_{i, j}\right) \\
& \text { WICCor }_{j, i}=\frac{\text { ENS }_{j, i} \times V O L L_{i}^{D i}}{\text { Simulation_year }_{-}} \\
& \text {WIFD }_{j}=\max \left(\text { Di_bas }_{j}\right) \\
& L O L=\text { load_curtailment }(t)
\end{aligned}
$$

WIICCor: $\quad$ Effect of the original interruption cost of the customers to the demand response value

WIFD: Weight index which shows the most frequent duration (mode) in hours at each load point under the baseline

Di_bas: $\quad$ Frequency of the duration of customer's interruptions of the baseline

LOL: $\quad$ Loss of Load at a given hour $\mathrm{t}$ 


\section{Proposed IBDR network modeling}

In order to determine the new shape of the system load and the network operational costs, a two-step IBDR that considers PSVS and EDR regimes is used in this paper. In this study the original load curve is given by [14] and its sequential modelling is set (in hours) from 8400 to 8568 hour (51 week). When the DSM of a network is considered the frequency and the duration of the interruptions as well as the interruption cost of the customers at the load points are taken into account. These factors are identified assuming, firstly, the occurrence of unexpected events, e.g. line, generator outages, and secondly the operation of the IEEE RTS without DSM strategy. Subsequently, four weight indexes are used as inputs of the proposed model. More specifically, WIbus and WIICCbas are considered for the management of the load in peak hours (1.4), (1.5); WIICCor and WIFD are used for the EDR model (1.8), (1.9), and are activated under contingency conditions. In this study, all consumers are assumed to participate voluntarily in the IBDR program; while no penalty is given if they do not comply with the DR rules (shift/ fill the load at off-peak times). Consumers' motivation relies on the fact that they receive prior notice either during peak demand or security violation. Consequently, the socioeconomic effect of probable loss of supply is substantially reduced.

Fig. 1 illustrates the flowchart of the calculations performed for evaluating the IBDR model, which calculates the new load profile, the total operational cost and the reliability indexes of the 24-bus IEEE RTS.

The steps of the methodology are explained below:

Step 1: Initially, the number of hours is set of the Sequential MC simulation year. For every hour a decision is made depending on whether demand is high or not.

Step 2: If the demand is larger than $80 \%$ of the peak load then the PSVS strategy is triggered. The DR value is applied to each user subject to its importance and it is limited within the range of $\pm 20 \%$ of the initial load.

Step 3: If the network is under a contingency condition and load shedding is applied at the load points, then emergency demand response (EDR) is used as corrective action.

Step 4: If the system is in normal condition no DR action is taken

Step 5: Evaluate the reliability indices

Step 6: The simulation proceeds to the next hour until convergence stopping criteria are fulfilled.

\section{NETWORK MODELLING CONSIDERING OHL THERMAL RATINGS}

\section{A. OHL Thermal Ratings modelling}

Many transmission companies usually use a fixed thermal rating for short-term and long-term planning studies, which is calculated assuming extreme weather conditions and maximum conductor temperature, which can be tolerated by the OHL system (conductor annealing and maximum sag). The fixed thermal rating is usually calculated for summer, due to higher ambient temperatures, which considerably affects the maximum capacity of the line. In this paper STR and TVTR thermal rating models are implemented as shown below:

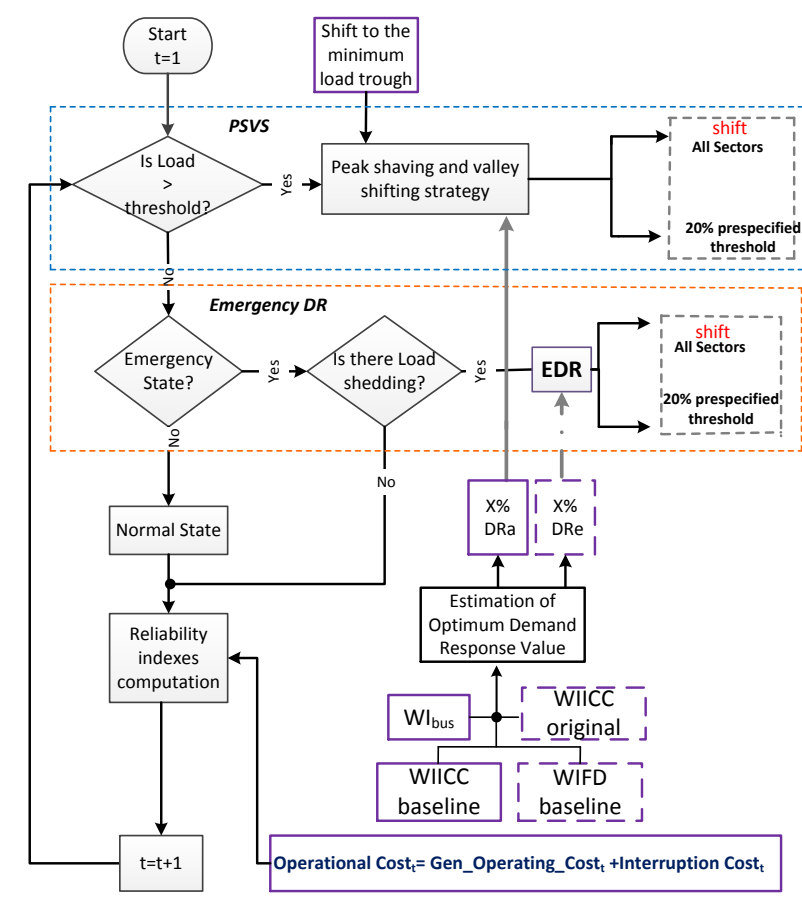

Fig. 1. Flowchart of IBDR model

1) STR: An annual fixed thermal rating based on $40{ }^{\circ} \mathrm{C}$ ambient temperature, $0.61 \mathrm{~m} / \mathrm{sec}$ wind speed perpendicular to the conductor and $60{ }^{\circ} \mathrm{C}$ and $75{ }^{\circ} \mathrm{C}$ conductor temperature for the normal and emergency operation respectively.

2) STR: An annual fixed thermal rating based on $40{ }^{\circ} \mathrm{C}$ ambient temperature, $0.61 \mathrm{~m} / \mathrm{sec}$ wind speed perpendicular to the conductor and $60{ }^{\circ} \mathrm{C}$ and $75{ }^{\circ} \mathrm{C}$ conductor temperature for the normal and emergency operation respectively.

3) TVTR: The TVTR model proposed in [6] is used to represent the real transmission capacity that is available on a given network. The wind speed $\left(\mathrm{V}_{\mathrm{m}}\right)$, direction $\left(\mathrm{K}_{\text {angle }}\right)$, and ambient temperature $\left(\mathrm{T}_{\mathrm{a}}\right)$ are used for the modeling of the OHL adequacy. The hourly weather data of 5 years from 1997 to 2001 were obtained from BADC Met office MIDAS stations for Aonach UK area [15]. In order to simplify the simulations the analysis was performed only for a year using the average value of each year for the hourly measurements $\left(\mathrm{V}_{\mathrm{m}}, \mathrm{K}_{\mathrm{a}}, \mathrm{T}_{\mathrm{a}}\right)$. Therefore, a single year of average values is used for the sequential analysis.

The IEEE RTS network studied here is assumed to have overhead line structures with a single Dove conductor configuration for the $138 \mathrm{kV}$ part and twin Hawk configuration conductor for the $230 \mathrm{kV}$ part.

\section{B. Selection of OHL for TVTR application.}

In practice, the implementation of TVTR of an OHL requires the usage of information infrastructure (i.e., communication links, instrumentation and control center). Due to the cost of employing TVTR to a whole network, it is critical to identify which OHLs should be prioritized for realtime thermal rating monitoring in a network. In this paper, the importance of each OHL is calculated subject to the 
followings: WIbus, the expected loading of the transmission lines (ELTL); and the marginal thermal rating usage (UMTR) of every OHL connected to a load point. For the selection of the most critical lines the maximum values of (1.11) are computed for both $138 \mathrm{KV}$ and $230 \mathrm{KV}$ voltage systems of the IEEE network respectively. In particular, for the calculation of the UMTR the nodal transmission line usage weight index is used (1.13), which is calculated for both emergency and intact system in order to capture the marginal capacity of a line when a violation of the system is incurred.

$$
\begin{aligned}
& \max \left(\text { WIbus }^{k} \times E L T L \times U M T R\right) \\
& E L T L_{k}=\frac{\sum_{s \in \Omega(t)} \operatorname{Pov}_{s}}{\text { Simulation_year }_{\text {ymurion }}} \\
& N T L U_{j, k}=\frac{N T r T_{j, k}}{\text { Total_ }_{-} \operatorname{NTCT} T_{j}}
\end{aligned}
$$

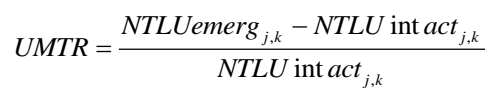

\section{Reliability Evaluation analysis}

Probabilistic reliability evaluation is implemented by using sequential $\mathrm{MC}$ in order to incorporate the DR model. In particular, the method considers that transmission lines are represented by a two state model: up and down. Exponential distribution function is used to identify the mean values of time to failure and time to repair of the lines and generators.

The index used in this paper to evaluate the reliability of implementing DR and TVTR is the energy expected not supplied (EENS, MWh/y) and is given by (1.15).

$$
E E N S=\sum_{i=1}^{N L}\left(\sum_{s e F_{i}} P(s) C(s)\right) T_{i}
$$

$\mathrm{C}(\mathrm{s})$ is the load curtailment in state $\mathrm{s}$

$\mathrm{P}(\mathrm{s})$ is the probability of system state $\mathrm{s}$

$\mathrm{NL}$ is the number of load levels

$T_{i}$ is the total number of the one period cycle (hours)

$F_{i}$ is the set of all system states associated with load curtailment

The estimate of EENS, its variance, and the coefficient of variation (COV) are defined by (1.16).

$C O V=\frac{\sqrt{\operatorname{Var}(E(F(x)))}}{E(F(x))}$
$\operatorname{Var}(\mathrm{E}(\mathrm{F}))$ is the variance of the estimated index.

Under normal operation (no outages occur) the conductor temperature, $\mathrm{T}_{\mathrm{c}}$, is set at $60^{\circ} \mathrm{C}$ based on avoidance of the conductor annealing [16], [17].

A line is defined to be at emergency state, when another transmission line connected on the same bus (as the one in emergency state) has failed. In cases a failure of a line does not result in a credible outage then lines are considered as being at normal operation state. In the present study under emergency operation the maximum conductor operating temperature is considered to be $75^{\circ} \mathrm{C}$.

\section{CASE STUDIES: ILLUSTRATION, VALIDATION AND ANALYSIS ON A 24-NODE NETWORK}

The effect of the customer's interruptions on the overall network performance is examined in the IEEE 24-bus RTS network. This system contains 38 lines and 32 generators of varying types such as hydro, coal/steam, nuclear. The total peak load of the system is $2850 \mathrm{MW}$, while the total generating capacity is 3405 MW.

The algorithm was developed on Matlab using modified Matpower for the power flow calculations [18]. The MIPS solver is used for the AC-OPF in Matpower with objective functions being the minimization of the load curtailment and the minimization of the generation costs.

The additional scenario with increased load to $1.2 \mathrm{pu}$ its normal load; with $0.55 \mathrm{pu}$ and $0.6 \mathrm{pu}$ (for the $138 \mathrm{KV}$ and $230 \mathrm{KV}$ respectively) is also used in order to determine the importance of each load point and set weight indexes with the view to facilitate network operators for practicing DSM programs (baseline). For this study the SMC technique is used assuming coefficient of variation (COV) to be lower than $5 \%$, as stopping criterion [19]. The load profile consists of the 51 peak weak. This interruption based study is performed for both intact and contingent network scenarios using STR model.

The results of the base case study indicate that B6 is the most frequently interrupted bus, due to lack of generation unit connected to this bus, as well as the high failure rates L5 and L10 lines that the bus is connected to. On the contrary, customers' interruption on B1 and B2 is negligible because of the big number of lines and generators, which are connected on them (Fig.2). The same graph illustrates the statistical mode of the duration of the interruptions. By observing the figure, it can be seen that most of the bars have more than 1 hour mean duration of their interruptions with the majority of the load points being interrupted for a 2 hours and 3 hours mode duration. Furthermore it can be observed that no load point has more than 3 hours mode interruption duration. In addition, it is shown that using DR only slightly reduces frequency of interruptions but a significant reduction is observed when using DR\&TVTR operation regime (Fig.5).

When considering the VOLL of the customers then the interruption cost of the various customer types at each load point is as shown in Fig. 4 on the left bars. Consequently, the percentage of the WIICC at each bus is different for each individual customer type due to the variation of the percentage of Large Users, Residential, Industrials, and Commercials at each load point, as indicated on the right bars in Fig. 4. It can be also observed that although the industrials hold the minimum percentage in most of the buses, their corresponding 


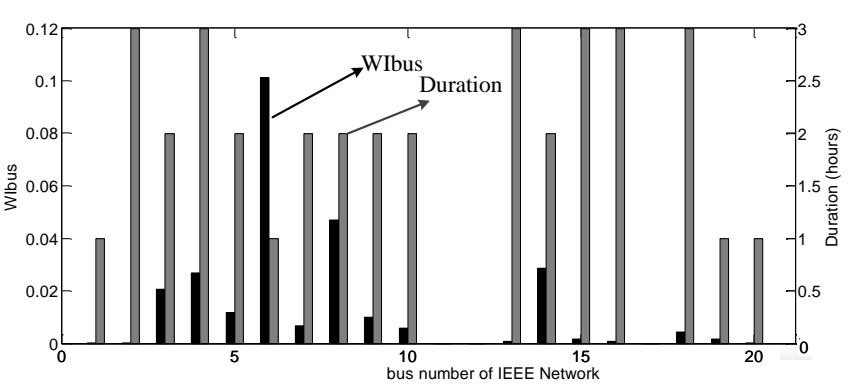

Fig. 2. Weight index of Frequency and Duration of each load point without DR

TABLE I.

RELIABILITY INDICES OF THE IEEE 24 BUS NETWORK

\begin{tabular}{|lccc|}
\hline \hline INDICES & Baseline & DR & DR\& TVTR \\
\hline EENS(MWh/wk) & 873.037 & 761.143 & 629.46 \\
TOC(M\$/wk) & 3314 & 2986 & 2816 \\
\hline
\end{tabular}

TABLE II.

TVTR OHL'S MAP OF THE IEEE 24 BUS NETWORK

\begin{tabular}{|ccccc|}
\hline \hline OHLS WITH TVTR & L11 & L12 & L23 & L28 \\
\hline BUSES AFFECTED & B7, & B8, & B14, & B16, \\
BY TVTR & B8 & B9 & B16 & B17
\end{tabular}

WIICC is the highest while the Residentials have the minimum WIICC in most buses. This is mainly due to the VOLL of Industrials is up to 31 times larger than the VOLL of the other customer types with the smallest VOLL related with residential users. Considering the bus B6 as an example, the Industrials are only $30 \%$ but the WIICC is $71 \%$ because the mode of duration of interruptions is 1 hour, in which the VOLL of Industrials reaches its highest value $(50.52 \$ / \mathrm{KW})$.

Table I illustrates the reliability performance of the network considering three case studies. The first includes the baseline, while the other two scenarios use DR as a corrective action for post fault analysis with STR and TVTR operation regimes. It is evidence from Table I that DR in conjunction with TVTR is the most secure and economic scenario. In particular, the TVTR and DR implementation resulted in 27.9\% lower EENS than the baseline (STR \& without DR model) while the improvement of the EENS when only DR is implemented (with STR) was found to be improved by $17.3 \%$ EENS from the baseline. This is mainly due to the ability of DR in alleviating the overloading of OHLs.

The Total Operating Cost (TOC) of the network, which considers both generation cost and cost of interruptions, decreases significantly, when DR and TVTR are implemented as during contingent conditions both cheaper generators and demand reduction can be utilized. Table I indicates the actual values of TOC and EENS.

The expected loss of load (LOL) of each individual load bus of the network is illustrated in Fig.4 for the two scenarios of DR that consider STR and TVTR of the transmission lines. Residential customers are mainly shifted due to the smarter AC-OPF provided by the DR_em function. This is more obvious when B6 and B8 are compared due to the heavy Residential load of B8 is resulting in 38\% higher LOL under DR scenario compared to B6. By further investigating these two buses the B8 has about $10 \%$ more residential load and $22 \%$ bigger VOLL than B6 due to the WIFD produced by the baseline (see Fig.2). When the DR with TVTR scenario is implemented the increased power transfer further reduces the

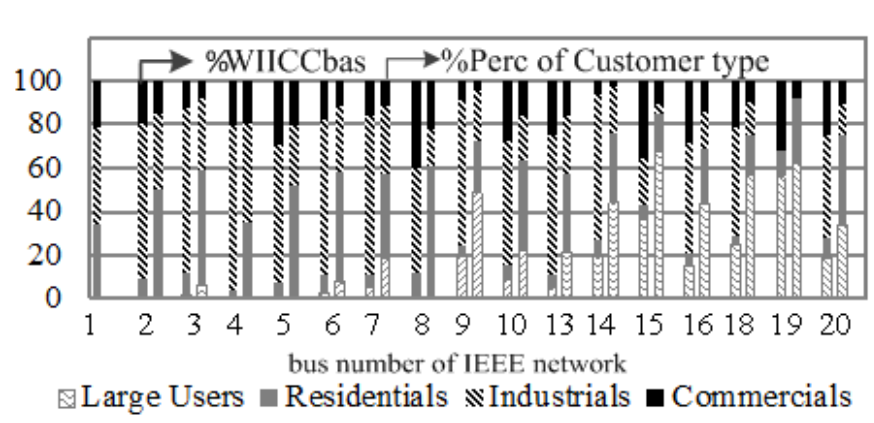

Fig. 3. Weight Index of interruption cost for each customer type

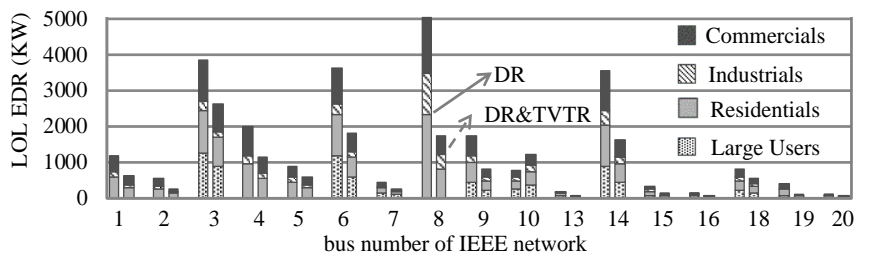

Fig. 4. Comparison of LOL under EDR

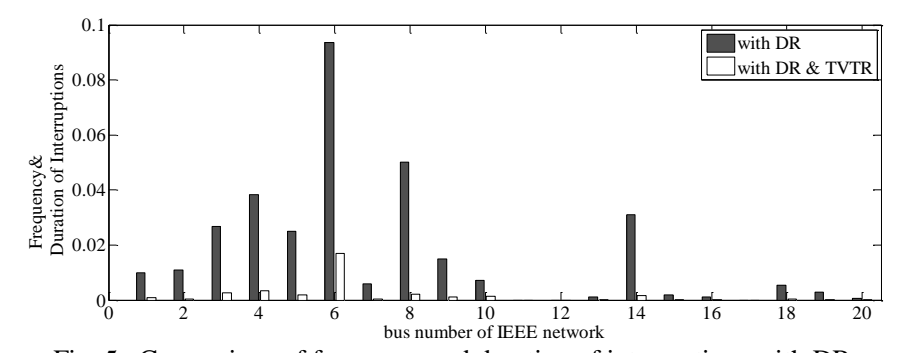

Fig. 5. Comparison of frequency and duration of interruptions with DR, DR\&TVTR

LOL at each bus resulting in almost identical LOL values for B6 and B8. The largest drop in LOL (66\%) is due to the TVTR implementation of L11 and L12 connected to B8 (Table II).

Fig. 6 compares the EENS and the Expected Interruption Cost (EIC) at each load point under STR with (DR) and without DR (baseline) as well as under DR with TVTR model (DR\& TVTR). Both EENS and EIC are higher in the baseline except for B3 due to no utilization of DR and fixed thermal rating of the OHL that are connected to this bus. In detail, EIC of B6, B8, B14 have been substantially reduced due to DR model, while a slight difference is seen in EIC of B4. Furthermore, the EENS and EIC of B8 and B14 have mainly affected by the TVTR employment due to the increased capacity of the OHLs connected on them. Consequently, it is shown that the EIC on B4, B8, B14 is negligible and more particularly 57\%, 90\%, $89 \%$ lower than the baseline respectively.

Fig.6 also illustrates the average duration of interruptions at each load point under DR with and without TVTR model. In addition the maximum and minimum duration of each bus is indicated with the "+" symbol. It can be inferred from the graph that the average duration of interruptions under TVTR and DR is reduced when compared to the DR only scenario due to the reduction of transmission system's contingencies. The only buses that have increased average duration of interruption are B2, B6, B14 and B20 because of voltage violations caused by increased power flows under TVTR scenario. However, this increase is very small. 


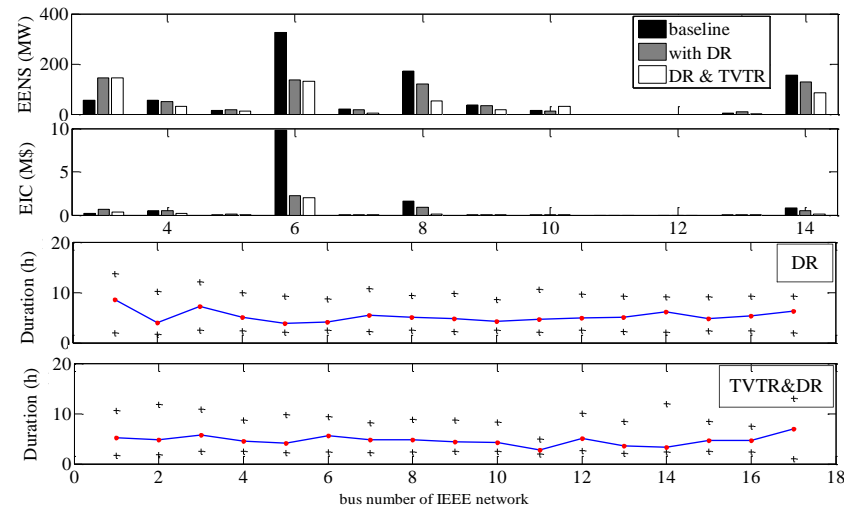

Fig. 6. Comparison of Expected Interrupted COST (EIC), EENS, Dr

TABLE III.

VOLL FOR DR AND TVTR MODEL OF IEEE 24 RTS

\begin{tabular}{|c|c|c|c|c|c|c|}
\hline \multirow{2}{*}{\multicolumn{2}{|c|}{ Bus }} & \multicolumn{4}{|c|}{ ECVOLL } & \multirow{2}{*}{$\begin{array}{c}\text { Duration } \\
\text { hours }\end{array}$} \\
\hline & & LU & Res & Ind & Com & \\
\hline \multirow{4}{*}{$D R$} & 4 & 0 & 2.62 & 38.06 & 24.47 & 5.12 \\
\hline & 6 & 5.501 & 2.47 & 39.53 & 24.89 & 4.06 \\
\hline & 8 & 0 & 2.63 & 37.86 & 24.57 & 5.03 \\
\hline & 14 & 5.15 & 2.62 & 38.09 & 24.56 & 5 \\
\hline \multirow{4}{*}{$\begin{array}{l}\text { DR\& } \\
\text { TVTR }\end{array}$} & 4 & 0 & 2.55 & 38.70 & 24.83 & 4.5 \\
\hline & 6 & 4.62 & 2.74 & 36.62 & 24.48 & 5.65 \\
\hline & 8 & 0 & 2.68 & 37.25 & 24.69 & 4.81 \\
\hline & 14 & 4.84 & 2.66 & 37.39 & 24.32 & 5 \\
\hline
\end{tabular}

Table III presents the ECVOLL and the average duration of interruptions for various customer types of the most critical buses. The ECVOLL, which is contingency Expected VOLL is developed as an additional index that affects the nodal pricing of the network and can be used to set the market spot price. This index is dependent on the network configuration (e.g. contingencies, DR, TVTR, loads, generation characteristics). It must be noted that the modified network characteristics lead to an average duration of interruptions for the load buses between 2.7 to 7 hours. This results from the analysis with no constraints for the number of outages of transmission lines and generators. The duration of failures of the lines and generators was found to be within the range of $6-26$ hours and from 12 30 hours respectively.

Fig. 7 shows that EENS improvement of many transmission lines compared to the baseline is substantial under both DR and DR\&TVTR schemes. This is due to DR operation eliminates OHL overloads on the transmission system.

\section{CONCLUSION}

This paper presents an analysis of network performance when DR regimes and TVTR are available to the operator. In order to allow for the sequential MC modeling of the network with DR and TVTR some methodological enhancements have been implemented. Those allow for the DR implementation based on prioritization of load points. This prioritization of critical load points is based on weight indices and factors that capture for each bus the interruption frequency and duration as well as the type of customer interruption to evaluate the cost of interruptions. Therefore, the contribution of DR to each

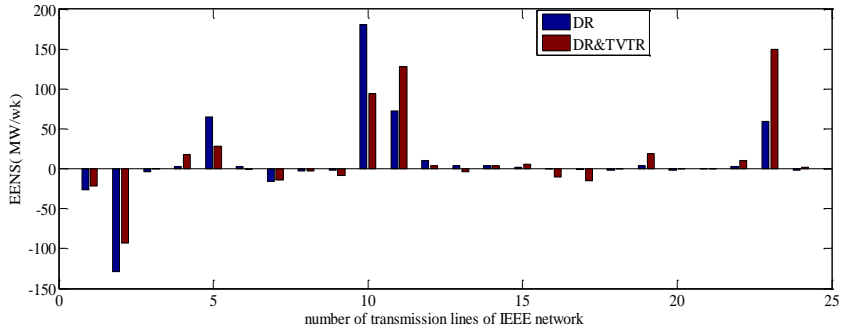

Fig. 7. Comparison of EENS improvement of transmission lines

network contingency cost can be identified evaluating the benefits from both STR and TVTR. In addition, the ECVOLL index is calculated that includes the duration of interruption on VOLL considering therefore the additional contingency cost.

The results show that DR and TVTR increase network reliability and reduce operation costs providing benefits to both customers and network operators by increasing operator's flexibility. When, DR with STR operation is implemented the total EIC of the 24-bus network is reduced by $60.6 \%$, while a further $42.5 \%$ reduction of the total EIC is achieved when both DR and TVTR operation are implemented. This signifies the importance of the TVTR implementation when DR regimes are employed.

\section{REFERENCES}

R. Azami, A. H. Abbasi, J. Shakeri, and A. F. Fard, "Impact of EDRP on composite reliability of restructured power systems," 2009 IEEE Bucharest PowerTech, pp. 1-6, Jun. 2009.

M. Zhou, G. Li, and P. Zhang, "Impact of Demand Side Management on Composite Generation and Transmission System Reliability," 2006 IEEE PES Power Syst. Conf. Expo., pp. 819-824, 2006.

M. Nikzad, M. Bashirvand, B. Mozafari, and A. M. Ranjbar, "Prioritizing demand response programs from reliability aspect," 2012 11th Int. Conf. Environ. Electr. Eng., pp. 229-234, May 2012.

K. K. Kari and R. N. A. I. Ian, "Evaluation of reliability worth and value of lost load," pp. 171-180.

D. S. Kirschen, K. R. W. Bell, D. P. Nedic, D. Jayaweera, and R. N. Allan, "Computing the value of security," in IEE Proceedings-Generation, Transmission and Distribution, the value of security," in IEE
2003 , vol. 150 , pp. $673-678$.

. A. Kapetanaki, K. Kopsidas, C. Tumelo-Chakonta, and M. Buhari, "Network
Evaluation Implementing Time Varying Thermal Ratings," in PMAPS, 2014.

C. Tumelo-Chakonta and K. Kopsidas, "Assessing the Value of Employing Dynamic Thermal Rating on System-wide Performance," in ISGT Europe, 2011, pp. 1-8. M. Fotuhi-Firuzabad and R. Billinton, "Impact of load management on composite system reliability evaluation short-term operating benefits," IEEE Trans. Power Syst., vol. 15, no. 2, pp. 858-864, May 2000.

W. M. Smith, L. J. Vogt, and H. L. Willis, "DEMAND-SIDE MANAGEMENT IMPACT ON THE TRANSMISSION AND DISTRIBUTION SYSTEM," vol. 5, no. 2, pp. 506-512, 1990.

M. A. Ortega-Vazquez and D. S. Kirschen, "Economic Impact Assessment of Load Forecast Errors Considering the Cost of Interruptions," pp. 1-8, 2006. FERC, "Regulatory commission survey on demand response and time based rate programs/tariffs."

J. Schachter and P. Mancarella, "A Short-term Load Forecasting Model for Demand Response Applications," in EEM14 - 11th International Conference on the European Energy Market, 2014, pp. 1-6.

Energy Market, 2014, pp. 1-6.
H. Aalami, G. R. Yousefi, and M. Parsa Moghadam, "Demand Response model

considering EDRP and TOU programs," 2008 IEEE/PES Transm. Distrib. Conf. Expo., pp. considering EDR 1-6, Apr. 2008.
C. Fong, S. Haddad, and D. Patton, “The IEEE Reliability test system-1996," vol. 14, no.

"http://badc.nerc.ac.uk/data/ukmo-midas/WPS.html."

K. Kopsidas, S. M. Rowland, S. Member, and B. Boumecid, "A Holistic Method for Conductor Ampacity and Sag Computation on an OHL Structure," IEEE Trans. Power Deliv., vol. 27, no. 3, pp. 1047-1054, 2012.

"IEEE Guide for Determining the Effects of High-Temperature Operation on Conductors Connectors, and Accessories," IEEE Std 1283-2004, pp. 1-28, 2005. R. D. Zimmerman, E. M.-S. Carlos, and D. Gan, "MATPOWER:A MATLAB Power System Simulation Package, Version 3.1b2, User's Manual." Power Systems Engineering Research center(PSERC), Tech. Rep. 2006, New York, 2011.

R. Billinton and W. Li, Reliability Assessment of Electrical Power Systems Using Monte Carlo Methods. New York: London:Plenum, 1994, pp. 35-36. 